\title{
Do senso comum à qualificação profissional: a construção da docência de bebês
}

\section{From common sense to professional qualifications: the construction of baby teaching}

Marilda Capitulina Costa Salgado Mestre em Educação pela Universidade Municipal de São Caetano do Sul Docente da Rede Municipal de Educação de São Caetano do Sul São Caetano do Sul, São Paulo - Brasil mccsalgado68@gmail.com

Marta Regina Paulo da Silva Doutora em Educação pela UNICAMP Docente-Pesquisadora do PPGE da Universidade Municipal de São Caetano do Sul São Caetano do Sul, São Paulo - Brasil martarps@uol.com.br

Resumo: Este trabalho apresenta os resultados de uma pesquisa realizada com educadoras de bebês em um município da Região do Grande ABC Paulista/SP. No intuito de compreender como essas educadoras vêm constituindo sua identidade profissional, utilizou-se como procedimentos metodológicos relatos orais, fontes iconográficas e documentais. Os resultados revelaram que, nos primeiros anos, o modelo de atendimento nos berçários era, exclusivamente, assistencialista. A qualificação das profissionais se deu por meio da iniciativa das gestoras responsáveis pelas instituições, uma vez que não havia profissionais com experiência e conhecimento para atuar com bebês. Diante das demandas que surgiam no dia a dia, as educadoras foram construindo suas práticas, com base em conhecimentos de senso comum e também naqueles construídos em ações formativas desenvolvidas por diretoras e professoras das próprias unidades educacionais que buscavam referenciais teóricos para qualificar o trabalho. É possível afirmar que a creche procurava construir sua própria identidade.

Palavras-chave: identidade professional; formação docente; relatos orais; docência de bebês.

\begin{abstract}
This paper presents the results of a survey conducted with educators of early childhood in a city based in São Paulo's metropolitan region known as Grande ABC. In order to understand how these educators have been developing their professional identity, the survey used oral reports, iconographic representations and documentary sources as methodological procedures. The results reveal that in the early years, the nurseries' care model was, exclusively, as social assistance. The qualification of the professionals took place through the initiative of the managers responsible for the institutions, since there were no professionals with experience and knowledge to work with babies. Facing the demands that arose on a daily basis, the educators have been building new techniques based on common knowledge and also based on knowledge built during training sections developed by principals and teachers in those educational units once they were also searching for theoretical references to qualify the paper. It's possible to conclude that the day care center wanted to build its own identity.
\end{abstract}

Key-words: professional identity; teacher training; oral reports; teaching of babies.

Cite como

(ABNT NBR 6023:2018)

SALGADO, Marilda Capitulina Costa; SILVA, Marta Regina Paulo da. Do senso comum à qualificação profissional: a construção da docência de bebês. Dialogia, São Paulo, n. 37, p. 1-16, e19764, jan./abr. 2021. Disponível em: https://doi.org/10.5585/dialogia.n37.19764.

American Psychological Association (APA)

Salgado, M. C. C., \& Silva, M. R. P. Da. (2021, jan./abr.). Do senso comum à qualificação profissional: a construção da docência de bebês. Dialogia, São Paulo, 37, p. 1-16, e19764. https://doi.org/10.5585/dialogia.n37.19764 
SALGADO, Marilda Capitulina Costa; SILVA, Marta Regina Paulo da. Do senso comum à qualificação profissional: a construção da docência de bebês

\section{Introdução}

Nos últimos anos, tem-se acompanhado o desenvolvimento de diversos estudos que revelam a potência dos bebês, capacidades que há tempos não eram reconhecidas e que atualmente precisam ser discutidas de modo mais amplo, sobretudo no que se refere a instituições que atendem crianças de 0 a 3 anos de idade, considerando a necessidade de se rever conceitos e concepções historicamente construídos, os quais influenciam diretamente as relações entre educadores(as) e crianças bem pequenas. Nesse sentido, discutir a construção do papel dos(as) profissionais que atuam com bebês nos espaços coletivos torna-se extremamente relevante, uma vez que ser educador(a) de bebês, mais do que gostar de crianças, exige profissionalidade e conhecimentos fundamentais que dizem respeito às especificidades desta faixa etária.

A constituição da identidade profissional dos(as) educadores(as) que atuam em berçários das inúmeras instituições públicas no Brasil configura-se, ainda, como um grande desafio, haja vista que se vive em um país com uma imensa diversidade, que engloba aspectos culturais, sociais, políticos e econômicos que influenciam diretamente as políticas públicas voltadas à área da educação. Além disso, é preciso considerar que a constituição identitária desses(as) profissionais se dá no âmbito de um processo histórico que se confunde com a história da própria creche e, portanto, a fim de se compreender quem são os(as) educadores(as) de bebês, é preciso primeiramente entender esse processo que levou à criação das creches.

A história revela que, no Brasil, a instituição creche não surge de uma preocupação com a infância, mas sim de demandas sociais, políticas e econômicas que atendiam aos interesses de uma classe dominante. As creches apresentam-se, desde o seu início, como um favor concedido à parcela pobre da população, o que justifica, em muitos municípios brasileiros, o pouco investimento ocorrido ao longo dos anos. Essas instituições carregam em sua história um estigma de serviço oferecido aos(às) "desvalidos(as)" - e, portanto, de baixa qualidade -, no qual alimentar, higienizar e preservar a saúde já era o suficiente para atender às necessidades das crianças pertencentes às classes sociais mais desfavorecidas.

O caráter assistencialista e de dominação que caracteriza o atendimento à infância pobre é abordado por Kuhlmann Júnior (1998) ao tratar acerca das instituições destinadas a esse público; segundo o autor, tal caráter revelava uma concepção de educação para a submissão das crianças das classes populares.

A creche, sob esse ponto de vista, em seus primórdios, colocava aqueles(as) que dela necessitavam em posição de humilhação, reféns de um serviço de baixa qualidade e de um assistencialismo que trazia em si uma pedagogia da submissão, cujo objetivo era o de manter a 
ordem social vigente. Assim, esse estigma de creche desqualificada acabou por produzir uma concepção que tem atravessado a história.

Nessa perspectiva assistencialista e autoritária, com escopo de controle, higienização e moralização, não havia preocupação no que concerne à formação dos(as) profissionais que atuavam com essa faixa etária. Isso porque, apoiados(as) em uma concepção que via a criança como frágil, passiva e incapaz de interagir com o mundo, tais profissionais desempenhavam o papel de cuidadores(as), compreendendo o cuidado como ação mecânica, sem a preocupação com vínculos afetivos, de maneira a reafirmar, portanto, a visão adultocêntrica, disciplinadora e moralizante inerente a esse modelo de educação.

Essas concepções atualmente ainda se fazem presentes em muitas instituições brasileiras, sendo parte constitutiva da identidade profissional dos(as) educadores(as). Uma outra marca dessa identidade é observada na massiva presença feminina em creches, bem como no preconceito e na desconfiança em relação à figura masculina, como se este profissional estivesse invadindo um espaço que historicamente não lhe pertence. Pode-se, ainda, destacar a desvalorização profissional que se revela nas precárias condições salariais e laborais presentes em muitas cidades brasileiras.

A potência dos bebês e o contexto histórico que envolve creches e educadores(as) impõem inúmeras reflexões que se fazem necessárias para se pensar em uma educação de qualidade que considere as especificidades da docência de bebês. Afinal, quem são os(as) educadores(as) que atuam em berçários? Quais concepções estão presentes em suas práticas? Como tais concepções foram se constituindo na docência de bebês?

Este artigo apresenta os resultados de uma pesquisa (SALGADO, 2018) realizada em um município da Região do Grande ABC Paulista, cujo objetivo foi compreender, por meio de relatos orais e de análise de fontes iconográficas e documentais, de que forma os(as) educadores(as) de bebês foram construindo saberes e fazeres que caracterizaram a constituição de sua identidade profissional.

1 Relatos orais e fotografias: narrativas que desvelam a história da educação de bebês

A constituição da identidade profissional de educadores(as) de bebês é bastante complexa, em virtude de se constituir sob um processo dinâmico que abrange distintos contextos e relações inter e intrapessoais diversas.

Refletir sobre as identidades profissionais de educadores(as) de infância, tal como aponta Sarmento (2016, p. 78), 
[...] obriga analisar um processo de construção social, no qual cada uma joga sua história de vida com a história de vida do grupo profissional a que pertence, com as crianças, com as comunidades e com contexto onde se desenvolve a sua ação educativa, transformando e permitindo-se transformar, nessa teia de interações numa forma própria de ser e agir.

Nesse sentido, ao se considerar os aspectos sociais e históricos presentes no objeto de estudo, o caminho metodológico que orientou a investigação em tela foi se delineando durante o próprio processo de pesquisa; nele foram surgindo relatos de educadoras de berçários e fontes iconográficas que forneceram informações ricas sobre o período em que as primeiras creches municipais foram instituídas, de modo que fizeram emergir dados históricos importantes que apresentavam estreita relação com a identidade profissional dessas profissionais. Soma-se a este fato a constatação de que não havia um registro sistemático da história das creches do município pesquisado; tal história encontrava-se em poder de quem a vivenciou.

A possibilidade de resgatar essa história, sob a perspectiva de por meio dela investigar marcas identitárias de educadores(as) de bebês, direcionou a pesquisa para um percurso metodológico que se apoiou em uma complementaridade de fontes, uma vez que utilizou relatos orais, fontes iconográficas e análise de documentos, sejam estes oficiais (Regimento escolar do município), sejam não oficiais (portfólios e registros das educadoras).

As fotografias surgiram na pesquisa antes mesmo dos relatos orais; foram elas que reavivaram memórias, fazendo despontar as narrativas orais. No momento em que as educadoras olhavam as fotos, reconheciam nelas suas próprias histórias, pois, tal como asseverado por Campos (1999, p. 77), “O registro fotográfico representa um fragmento da realidade social e a tarefa do pesquisador é ir além desse fragmento, isto é, situar esta visão parcial da realidade no contexto em que ela foi produzida e a partir dos interesses que norteiam o estudo".

As fotografias, material retirado de caixas e de álbuns pertencentes às próprias educadoras, tiveram um papel fundamental na reconstrução da história dos berçários, haja vista que serviram como um disparador de emoções, oportunizando a narração de relatos históricos importantes. No entanto, sua força enquanto documento é ainda maior, pois as imagens reveladas pelas educadoras talvez constituam os únicos registros de episódios de vida nas creches, os quais, quando reunidos, compõem a história da educação de bebês nesse município.

A despeito de muitas fotografias não possuírem datas para que pudesse ser feita uma identificação precisa dos períodos a que cada uma se referia, as memórias das educadoras foram fundamentais nesse sentido, pois as profissionais se basearam em elementos fornecidos pelas próprias imagens; ao olhar para as crianças, os colegas e a forma como os espaços estavam organizados, elas conseguiram estimar o ano em que as fotos haviam sido tiradas. 
Segundo Lucena (2001), a fotografia, ao ser tomada como auxílio para reavivar lembranças, estabelece o elo entre os dois tempos pesquisados: o passado e o presente. Os retratos conduziram as educadoras a uma sequência de eventos; mais do que descrever as fotografias e relatar o que acontecia naquele instante específico, as imagens lhes despertaram lembranças de fatos carregados de sentimentos, conduzindo a comparações sobre o que foi e o que é atualmente a creche.

Por meio das fotografias foi possível percorrer um período histórico em que a concepção que os(as) adultos tinham dos bebês se revelava pela forma como eram organizados os espaços, pela escolha dos mobiliários, pela decoração das salas, bem como pelas ações desses(as) adultos e por outros elementos, como, por exemplo, a maneira como as educadoras se vestiam; as imagens revelam que, à medida que a concepção muda, os espaços também se transformam. Como fonte de análise, pode-se afirmar que as fotografias caminharam lado a lado com os relatos orais, ao corroborar fatos narrados e, assim, complementar os depoimentos, oportunizando uma melhor compreensão acerca da realidade pesquisada.

O entendimento do presente passa por uma necessária análise de fatos que ocorreram no passado e que, invariavelmente, contribuíram para o momento atual; trata-se, portanto, de perceber o presente reconhecendo-o como produto histórico. Afirma Demartini (2013, p. 231): “se o conhecimento do presente é importante, há outra dimensão do problema que não pode ser ignorada, e, ao contrário, 'deve' também ser pesquisada: trata-se da análise das questões segundo uma perspectiva histórica, isto é, procurando conhecer os fatos através do tempo".

Logo, as narrativas, a partir dessa concepção histórico-sociológica, forneceram dados relevantes acerca de que espaço é este dedicado ao atendimento a bebês e como ele foi se configurando ao longo dos anos, sendo revelado por meio do olhar de quem viveu - e ainda vive - o cotidiano das creches. Os relatos propiciaram também informações sobre as próprias educadoras, indicando a forma como se relacionavam com as crianças e com sua profissão.

Demartini (2016, p. 286) considera que as memórias dos(as) educadores(as) possibilitam

[...] apreender formas insuspeitas de relações de aprendizagem entre crianças, [...] perceber como as culturas e identidades de educadores e de educandos estão presentes na prática pedagógica, imprimindo suas marcas nas culturas escolares, como a atuação dos professores pode se pautar mais pelos relacionamentos estabelecidos no contexto sócio-político vivenciado, apresentando resistências às determinações oficiais e os diferentes posicionamentos frente às metodologias de ensino.

$\mathrm{Na}$ pesquisa qualitativa, as narrativas, além de constituírem instrumento metodológico de coleta de dados, contribuíram para o trabalho formativo, na medida em que possibilitam ao sujeito rever sua história, de forma a reorganizar e a ressignificar determinadas experiências que podem direcioná-lo a uma nova compreensão e a um novo posicionamento diante de sua prática. $\mathrm{Na}$ ótica 
de Nóvoa (1988, p. 116), as histórias de vida e o método (auto)biográfico integram-se no movimento atual que procura repensar as questões da formação, acentuando a ideia de que “ninguém forma ninguém” e que a formação, inevitavelmente, é um trabalho de reflexão sobre os percursos de vida.

No tocante à escuta dos relatos das educadoras, optou-se, como campo de pesquisa, pelas duas primeiras instituições municipais a oferecerem atendimento a bebês. Tal postura se justifica, pois nelas ainda atuam algumas profissionais que iniciaram o trabalho desde a inauguração dessas entidades. A escolha dos sujeitos obedeceu ao critério de estes terem atuado com bebês nessas instituições, seja como professoras, auxiliares da primeira infância ou como diretoras que participaram da implantação de um projeto formativo intitulado "Projeto Bebê 2000".

As narrativas abordam experiências vividas por seis educadoras, sendo uma diretora, três professoras e duas auxiliares da primeira infância, mulheres que foram marcadas e que deixaram marcas que atualmente contam a história dos berçários desse município. Os relatos abrangem os anos iniciais de atendimento na primeira creche municipal (Creche A), inaugurada em 1984 sob a tutela da Secretaria de Assistência Social; o atendimento na primeira creche inaugurada em 1988 sob responsabilidade do Departamento de Educação e Cultura (Creche B); e, também, o Projeto Bebê 2000, considerado pelas educadoras a primeira iniciativa de ação formativa dedicada exclusivamente às auxiliares da primeira infância.

\section{Docência em berçários: saberes e fazeres construídos no cotidiano das creches}

A história dessas duas creches revela a perspectiva assistencialista presente nas instituições que atendiam crianças de 0 a 3 anos naquele período histórico, ou seja, na década de $1980 . \mathrm{Na}$ Creche $\mathrm{B}$, as profissionais que iniciaram o trabalho - denominadas pajem - tinham, naquele momento, seu primeiro contato com crianças pequenas; a opção por trabalhar com bebês partia das próprias educadoras, que se julgavam habilitadas para executar esse trabalho. Uma das professoras relata:

Professora 3: Os berçários eram formados por educadoras, exclusivamente auxiliares e, nessa primeira formação, [...] a diretora fez uma reunião e perguntou quem tinha interesse em trabalhar nos berçários e aí, algumas das auxiliares se candidataram. [...] E foi assim o critério de escolha, porque ninguém tinha tido, até então, experiência em trabalhar com os bebês. (SALGADO, 2018, p. 226)

Na Creche A, que em 1990 foi reinaugurada sob a responsabilidade do Departamento de Educação, logo em seu início, isto é, em 1984, tinha o foco do trabalho e a concepção presente caracteristicamente marcados pelo assistencialismo. As pajens dessa unidade acompanharam essa 
mudança de sede e tinham, à época, uma experiência de aproximadamente cinco anos na atuação com bebês. À semelhança da experiência vivenciada na Creche B, não existiam critérios para a escolha das auxiliares; contudo, nesta instituição, havia um período no qual as profissionais eram observadas por uma professora - que atuava com outros grupos de crianças - e pela diretora, no que concerne à maneira como "tratavam” as crianças. Nas palavras da professora:

Professora 2: A “A” [referindo-se à diretora], quando as auxiliares chegavam naquela época, eu lembro que ela até conversava comigo pra ver se a pessoa tinha mais vínculo com a criança, como ela tratava a criança. [...] se a pessoa chegasse e falasse que não gostava, ela trocava. Era bem flexível, ela não vinha com um perfil para o berçário, ela ia fazendo experiência dentro da escola, a gente ia conversando e a própria pessoa escolhia. (SALGADO, 2018, p. 222)

Observa-se que o desconhecimento sobre o trabalho a ser realizado e a compreensão acerca das crianças sob um aspecto exclusivamente de proteção e guarda fez com que a afinidade com bebês se tornasse o único critério de seleção. Além disso, a feminização do trabalho apresenta-se como marca das creches, revelando uma ideia de maternagem, o que, a priori, garantiria uma atenção aos cuidados físicos, no entanto, com base em um olhar doméstico em um espaço que deveria se constituir primordialmente como profissional.

Essa prática assistencialista se afirmava em espaços estruturados com muitos berços e cercadinhos, elementos reveladores de concepções higienistas e adultocêntricas que foram sendo naturalizadas em nome da preservação da integridade física das crianças. A preocupação era com a guarda e proteção, que aliada à falta de conhecimento sobre o potencial dos bebês, produzia práticas que limitavam não apenas as experiências das crianças, mas também o olhar e a escuta das educadoras.

As dificuldades vividas nestes primeiros anos, somadas ao incômodo gerado pela situação em que se encontravam os bebês, foram os desencadeadores da necessidade de se buscar conhecimento. Assim, ações isoladas de formação nas próprias unidades, a partir da iniciativa de diretoras e de professoras, fizeram surgir grupos de estudos voltados à formação das auxiliares, bem como ações de acompanhamento e intervenção nos berçários. As auxiliares descrevem:

Auxiliar 1: Então, aquilo era angustiante, ver eles querendo sair e não podia sair, eles choravam, foi muito difícil no começo. E foi, assim, uma coisa maravilhosa que aconteceu. Então, a A, ela reunia a gente na hora do almoço, então, ela fazia reunião com a gente, como ela gostaria que fizesse né? Foi sendo feita uma adaptação do berçário até a fase 1. (SALGADO, 2018, p. 184). 


\begin{abstract}
Auxiliar 2: Quem orientava era a diretora e as professoras que tinham na escola. Foi, assim, muito bacana com a gente porque você ficava perdido. Tinha hora que chorava todo mundo né? E com muito mais crianças que "veio", então, a "S" [referindo-se a uma professora] foi dando uma orientação pra gente, como que a gente deveria fazer. (SALGADO, 2018, p. 184).
\end{abstract}

Os relatos supratranscritos das educadoras demonstram que, naquele momento, havia uma tentativa de suprir as deficiências no atendimento aos bebês, porém, sem que houvesse um direcionamento e sem bases teóricas. De acordo com o descrito pela Professora 1, “[...] foi uma coisa meio que de forma instintiva, de ver a necessidade de que tinha que ter alguma coisa, porque os bebês ficavam só deitadinhos, comendo [...] não tinham outras ações com eles, era uma ou outra que sentava, cantava, mas não era uma prática”. (SALGADO, 2018, p. 209). No entanto, havia o desejo de encontrar referenciais teóricos que orientassem tais ações, mas, como relatado pela Professora 3, as aprendizagens ocorriam por "tentativa e erro" (SALGADO, 2018, p. 226), pois era escassa, naquele período, a literatura acerca da educação de bebês.

É curioso observar que esse movimento de formação, no âmbito das próprias unidades, não era considerado, sob a ótica das educadoras, como ações formativas, já que elas indicaram o Projeto Bebê, o qual teve início em 1998, como a primeira iniciativa de qualificar o trabalho dos berçários. Concomitantemente ao referido projeto, aconteciam ações formativas realizadas por uma instituição privada contratada em 1999 pelo município, a qual atuava na formação de professores(as) de creches e de pré-escolas. Porém, de acordo com o relatado pelas educadoras, não havia - até o surgimento do Projeto Bebê 2000 - qualquer formação específica para as auxiliares de berçário. A Professora 3 narra: “[...] quem dava o apoio era a própria escola. [...]. Nós nos reuníamos [...] umas 2, 3 vezes por semestre [...] era mais em relação ao cuidar do que o educar [...] a gente se reunia, estudava aquele assunto [...] para depois cada uma implantar na sua creche" (SALGADO, 2018, p. 226).

As ações formativas que se deram nos primeiros anos tinham foco em questões relacionadas exclusivamente aos cuidados com saúde e proteção. As educadoras desconheciam outra forma de atuar senão aquela de se colocarem como figuras centrais nas ações com os bebês. A manutenção dos berços significava não só proteção às crianças, mas também uma forma de organização econômica do trabalho; mantê-las em berços e em carrinhos exigia um número menor de adultas para despender os "cuidados" necessários. Contudo, constata-se por meio dos depoimentos que havia um incômodo gerado pelo choro dos bebês quando estes ficavam nos berços e nos "chiqueirinhos", configurando-se um dos fatores que contribuíram para que se procedesse à reestruturação do espaço. Nota-se também que havia a preocupação acerca da 
possibilidade de os bebês maiores machucarem os menores, apreensão esta que, por muito tempo, foi motivo de resistência para a retirada completa dos berços.

Logo, a retirada dos berços - e posterior reorganização do espaço em todas as creches do município - não se deu de forma tranquila, já que houve resistência tanto por parte de gestores(as) como de educadoras auxiliares. Os berços constituíam a representação de concepções assistencialistas muito arraigadas; no entanto, sua retirada trouxe liberdade aos bebês e às educadoras, as quais foram gradativamente superando conceitos e fazeres já há muito tempo assentados e cristalizados.

É possível afirmar que o Projeto Bebê 2000 foi o primeiro projeto oficial destinado à formação das auxiliares, educadoras de bebês, tendo sido idealizado e desenvolvido por um grupo composto por duas diretoras e uma professora. Sua duração foi de dois anos e, como resultado, produziu mudanças significativas nas práticas das educadoras, oportunizando um novo olhar sobre os bebês.

As bases desse projeto possuem como referência o trabalho desenvolvido na Creche Carochinha, na cidade de Ribeirão Preto, estado de São Paulo. No que concerne à concepção do projeto, a diretora relembra:

Diretora: [...] nós conversamos com a secretária [de Educação], dizendo que as crianças
ficavam muito em berços, em carrinhos, que eles precisavam ter um pouco mais de
autonomia e ela pediu pra que a gente fizesse um projeto, e aí se intitulou Projeto Bebêt
2000. Na verdade, na época, foi assim bem direcionado às auxiliares mesmo, nós fomos
buscar fora uma capacitação pra que nós sistematizássemos um trabalho pra estar junto
com elas. A gente foi na Creche Carochinha, em Ribeirão Preto. Levamos todas as
diretoras daqui primeiro pra conhecerem o local e depois a gente começou a fazer esse
trabalho com elas. (SALGADO, 2018, p. 236).

Apesar do curto período em que o Projeto Bebê foi desenvolvido, ele apresentou resultados positivos, que refletiram tanto na vida dos bebês quanto na das educadoras. Muitas destas passaram a buscar referências teóricas e formação no Magistério, visando a um melhor desempenho de sua função. Configurou-se, também, como um período muito produtivo, em que houve grande investimento na produção de materiais e na organização de ambientes para a exploração por parte dos bebês.

Das narrativas das educadoras, um aspecto sobretudo se destaca, a saber: a mudança do olhar em relação às competências e ao potencial dos bebês. A Professora 3 aduz:

Professora 3: [...] Eles iam para debaixo dos berços e o que nós começamos a fazer? Colocar coisas debaixo dos berços para eles irem pra debaixo dos berços porque, em um primeiro momento, a gente tinha um pouco de receio que eles se machucassem debaixo dos berços, porque os berços eram de ferro, então, a gente deixava os berços de um lado 
e eles só do outro, e aí a gente foi percebendo que o bebê não tem fronteira né? Bebê não tem espaço, não tem fronteira. (SALGADO, 2018, p. 231).

Esse relato revela a descoberta da potência dos bebês, a qual só pôde ser notada quando eles foram colocados em situações que lhes propiciaram movimento autônomo. As ações das educadoras anteriormente limitavam e direcionavam as ações dos bebês, mas, a partir dessa observação, as ações dos bebês é que passam a direcionar as ações das educadoras. Logo, o movimento deles passa a ser experienciado pelas educadoras "como convite ao brinquedo, à reestruturação do espaço, à cooperação" (SIEBERT, 1998, p. 83).

A compreensão acerca do significado de autonomia só surgiu quando as educadoras puderam constatar, por meio de situações práticas, o que os bebês conseguiam realizar por si próprios. A partir dessa observação, foi possível entendê-los na maneira como se envolvem, isto é, de forma espontânea e ativa, de forma a buscar sentido para as coisas e para os eventos que acontecem à sua volta, estando, portanto, em constante processo de construção de significado, tal como apontado por Tardos (2014). A diretora revelou que os espaços vazios começaram, intencionalmente, a se transformar em ambientes, concebidos e construídos com a participação das auxiliares, apoiadas nas observações que elas faziam dos bebês e de suas múltiplas linguagens.

A compreensão de que os bebês se comunicam por meio de "cem" linguagens (MALAGUZZI, 1999) é uma premissa na docência de bebês. Nos primeiros anos das creches, essa linguagem estava, de certa forma, emudecida, sendo o choro a linguagem utilizada pelos bebês para expressarem o desconforto dos corpos silenciados. À medida que as educadoras passaram a compreender as linguagens dos bebês, elas se puseram a escutá-los ao longo de suas rotinas. Em consonância com o relatado pela Professora 1, a escuta passa pela observação dos detalhes, isto é, "das minúcias" presentes nas ações dos bebês, revelando seus interesses e a forma como enxergam o mundo. Nas palavras desta educadora: "O olhar muda, você fica mais focada em pequenas coisas, e isso, você só aprimora esse olhar, este foco, passando pelos bebês, porque eles... são eles que têm as minúcias, os pequenos" (SALGADO, 2018, p. 218).

Esse depoimento revela uma relação de aprendizagem recíproca, em que educadoras e bebês aprendem em comunhão. Consoante Silva (2020), o bebê é sujeito de sua formação e, portanto, precisa ser respeitado como tal; nesse sentido, a escuta de suas vozes faz-se fundamental, o que implica presença, disponibilidade e atenção a eles e às suas produções. "Trata-se de uma relação potente, marcada pelo acompanhamento e companheirismo que se estabelece entre o(a) educador(a) e o bebê” (SILVA, 2020, p. 283).

Essa relação possibilita uma comunicação cada vez mais clara, como explicita Chokler (2017, p. 69): 
[...] existe una relación dialéctica entre apego, comunicación y exploración. [...] el niño explora las características de los adultos para brindarle con la respuesta específica a sus necesidades y deseos y recíprocamente el adulto explora y va conociendo las necesidades y modalidades expresivas del niño.

A relação com as famílias constitui aspecto relevante na atuação com os bebês nas instituições e deve ser compreendida como inerente à função do(a) educador(a). A maneira como as educadoras se relacionam com as famílias dos bebês, bem como a forma pela qual estas são percebidas pelas educadoras, revelam o que consideram seu papel enquanto profissionais e quais expectativas as famílias têm a seu respeito.

Os relatos das educadoras evidenciam diferentes aspectos dessa relação. A Auxiliar 1 pontua que a creche, em seu início, estabelecia com as famílias uma relação muito distante, a qual foi se transformando ao longo dos anos. As famílias consideram ser papel da educadora a garantia da integridade física e dos cuidados com alimentação e higiene. Primeiramente, esse papel foi assumido pelas educadoras como pertença, ou seja, a identidade que elas têm de si mesmas coincide com aquilo que lhes é atribuído pelas famílias. Porém, verifica-se o empenho dessas profissionais em apresentar às famílias outras atribuições que estão além dos cuidados com higiene e alimentação; isso foi sendo realizado por meio de reuniões com as famílias e de organização de registros e de portfólios que evidenciam as práticas das educadoras na relação com os bebês. Há, nesse sentido, uma resistência às atribuições de "cuidadoras", que, segundo apontam os relatos, ainda lhes são imputadas pelas famílias.

Por intermédio dos depoimentos, as professoras mostram que há uma cisão entre o cuidar e o educar. Em suas narrativas, elas pontuam que os cuidados devem ser superados, porém, estes estão presentes em todo momento da rotina dos berçários, constituindo parte importante do trabalho e, portanto, pertencem também às atribuições pedagógicas, ao se considerar cuidar e educar como dimensões indissociáveis, uma vez que:

$\mathrm{O}$ ato de cuidar ultrapassa processos ligados à proteção e ao atendimento das necessidades físicas. Cuidar exige colocar-se em escuta às necessidades, aos desejos e inquietações [...] cuidar e educar significa afirmar na educação infantil a dimensão de defesa dos direitos das crianças, não somente aqueles vinculados à proteção da vida, mas também aos direitos universais de aprender a sonhar, a duvidar, a pensar, a fingir, a não saber, a silenciar, a rir e a movimentar-se. (BRASIL, 2009, p. 69). 
Semelhantemente aos relatos das professoras, é possível notar também no discurso da diretora a oposição entre cuidar e educar: "elas voltaram a cuidar", referindo-se ao momento atual. Porém, o cuidado nunca deixou de existir: somos seres que cuidam e que precisam de cuidados. E isso se faz necessário no espaço dos berçários, devendo estes serem entendidos de forma não dicotomizada da dimensão do educar (BARBOSA, 2010).

Por fim, entende-se que pensar o cuidar e o educar sob uma perspectiva de oposição pode conduzir ao engano de que o cuidado não exige intencionalidade e qualificação; essa dicotomia produz marcas que são elementos da identidade profissional da educadora de bebês.

\section{Considerações finais}

A constituição da identidade das educadoras de bebês do município investigado tem suas raízes em duas creches inauguradas na década de 1980. Nesse período, a despeito das mudanças acarretadas pela Constituição Federal (BRASIL, 1988), não havia o reconhecimento da profissão de professor(a) de creche. $\mathrm{O}$ atendimento a bebês representava um grande desafio a toda a equipe educativa, visto que essas instituições traziam marcadamente uma característica de serviço assistencialista e, portanto, desqualificado.

Sob esse cenário, as atribuições foram impostas às educadoras pelas próprias demandas do trabalho com os bebês, sendo, desse modo, assumidas como pertenças e se configurando como parte da identidade profissional dessas educadoras, visto que "a construção das identidades faz-se, pois na articulação entre os sistemas de ação que propõem identidades virtuais e as trajetórias vividas, no interior das quais se forjam as identidades reais a que aderem os indivíduos" (DUBAR, 1997, p. 108).

Durante a trajetória profissional dessas educadoras, houve momentos nos quais as atribuições foram assumidas como suas e, em outros, foram questionadas ou mesmo negadas, o que revela que o processo de constituição da identidade é dinâmico e se transforma de acordo com os diferentes contextos e momentos históricos; no âmbito desse processo, alguns elementos constitutivos dessa identidade podem ser observados.

As primeiras ações formativas direcionadas às educadoras surgiram a partir de iniciativas de diretoras e de professoras que dispunham de parte do seu período de trabalho para se dedicarem à formação das educadoras de berçário. A presença dessas profissionais com formação em Magistério à frente de todas as ações formativas mostra que a figura do(a) professor(a) no berçário é fundamental, dadas as especificidades que envolvem a educação de bebês. Essa docência exige saberes e fazeres sustentados por conhecimentos científicos, intencionalidade, observação e 
SALGADO, Marilda Capitulina Costa; SILVA, Marta Regina Paulo da. Do senso comum à qualificação profissional: a construção da docência de bebês

reflexão, o que se contrapõe às propostas dos anos iniciais desse atendimento no município analisado, nas quais os fazeres se pautavam em práticas de cunho doméstico e de senso comum. Foi possível constatar, por meio dos relatos, imagens e documentos, que o processo de formação vivenciado pelas educadoras, sobretudo durante o Projeto Bebê 2000, permitiu que o modelo assistencialista fosse, gradativamente, dando lugar a um atendimento pautado no conhecimento sobre bebês e sua educação.

A concepção de que bebês se comunicam por meio de muitas linguagens foi construída pelas práticas e ações formativas que colocaram as educadoras diante de reflexões sobre os seus fazeres. Além disso, essas educadoras foram desenvolvendo a capacidade de ler essas diversas linguagens, por intermédio de uma escuta atenta, compreendida por elas como "olhar" e "observação". O sentido de interação foi ampliado, uma vez que as interações se davam nos primeiros anos, essencialmente entre educadoras e bebês, porém, essas interações aconteciam sob uma relação verticalizada, que dependia unicamente das ações da educadora em direção aos bebês. É possível afirmar que essas educadoras atualmente concebem os bebês como seres potentes, que se expressam e que interagem no mundo por meio de múltiplas linguagens.

A história da constituição da docência de bebês nesse município analisado demonstra que a garantia de um(a) professor(a) nos berçários é um direito dos bebês, e também que a complexidade que envolve a docência de bebês exige uma sólida qualificação profissional, o que significa assegurar a este(a) educador(a) uma formação continuada em serviço, pois, caso contrário, corre-se o risco de constantes retrocessos que conduzam ao antigo modelo assistencialista.

\section{Referências}

BARBOSA, M. C. S. As especificidades da ação pedagógica com os bebês. In: SEMINÁRIO NACIONAL: CURRÍCULO EM MOVIMENTO - PERSPECTIVAS ATUAIS, 1. 2010, Belo Horizonte. Anais... Belo Horizonte: 2010. p. 1-17. Disponível em:

http://portal.mec.gov.br/docman/dezembro-2010-pdf/7154-2-2-artigo-mec-acao-pedagogicabebes-m-carmem/file. Acesso em: 01 jun. 2020.

BRASIL. Constituição da República Federativa do Brasil. Brasília, DF: Planalto, 1988. Disponível em: www.planalto.gov.br/ccivil_03/Constituicao/Constituicao.htm. Acesso em: 15 jun. 2020.

BRASIL. Ministério da Educação. Secretaria de Educação Básica. Indicadores da Qualidade na Educaşão Infantil. Brasília: MEC/SEB, 2009.

CAMPOS, M. C. S. de S. A associação da fotografia aos relatos orais na reconstrução históricosociológica da memória familiar. In: LANG, A. B. da S. G. (org.). Reflexões sobre a pesquisa sociológica. São Paulo: CERU, 1999. p. 73-86. 


\section{Dialogia}

SALGADO, Marilda Capitulina Costa; SILVA, Marta Regina Paulo da. Do senso comum à qualificação profissional: a construção da docência de bebês

CHOKLER, M. H. La aventura dialógica de la infancia. Buenos Aires: Ediciones Cinco, 2017. p. 4573.

DEMARTINI, Z. de B. F. Algumas anotações sobre história de vida e a prática de pesquisa em educação. Revista Pedagógica, Chapecó, v. 15, n. 31, p. 229-247, jul./dez. 2013. DOI: https://doi.org/10.22196/rp.v15i31.2337. Disponível em:

https://bell.unochapeco.edu.br/revistas/index.php/pedagogica/article/view/2337. Acesso em: 5 fev. 2021.

DEMARTINI, Z. de B. F. Memórias que interrogam: formação e atuação docente. In: SOUZA, E. C.; ABRAHÃO, M. H. M. B. (orgs.). Tempos, narrativas e fiçcões: a invenção de si. Porto Alegre: EDIPUCRS: EDUNEB, 2016. p. 279-296.

DUBAR, C. A. A socialização: construção das identidades sociais e profissionais. São Paulo: Martins Fontes, 1997.

KUHLMANN JÚNIOR, M. Infância e educação infantil: uma abordagem histórica. Porto Alegre, 1998.

LUCENA, C. T. Relembranças e representações de populações migrantes: entre a oralidade e a imagem. In: LANG, A. B. da S. G. (org.). Desafios em ciências sociais. São Paulo: CERU, 2001. p. 113-137.

MALAGUZZI, L. História, ideias e filosofia básica. In: EDWARDS, C.; GANDINI, L.; FORMAN, G. As cem linguagens da criança. Porto Alegre: Artmed, 1999. p. 59-104.

NÓVOA, A. A formação tem que passar por aqui: as histórias de vida no projeto Prosálus. In: NÓVOA, A.; FINGER, M. (orgs.). O método (auto)biográfico e a formação. Lisboa: Ministério da Saúde, 1988. p. 107-129.

SALGADO, M. C. C. Educadoras de bebês: desafios na construção da identidade profissional. 2018. 246 f. Dissertação (Mestrado Profissional em Educação) - Programa de Pós-Graduação em Educação, Universidade Municipal de São Caetano do Sul - USCS, São Caetano do Sul, 2018. Disponível em: www.uscs.edu.br/pos-stricto-sensu/ppge/mestrado-profissional-emeducacao/acervo/2018/TRABALHO_FINAL_MARILDA_CAPITULINA_COSTA_SALGA DO.pdf. Acesso em: 30 abr. 2021.

SARMENTO, T. Infâncias e crianças. In: PASSEGGI, M. da C.; FURLANETO, E. C.; PALMA, R. C. D. (orgs.). Pesquisa (auto)biográfica, infâncias, escola e diálogos intergeracionais. Curitiba: CRV, 2016. p. 77-94.

SIEBERT, R. O adulto frente à criança: ao mesmo tempo igual e diferente. In: BONDIOLI, A.; MANTOVANI, S. (orgs.). Manual de Educação Infantil de 0 a 3 anos. 9. ed. Porto Alegre: Artmed, 1998. p. $77-87$.

SILVA, M. R. P. da. "E os bebês?": quando os bebês interrogam a nossa docência. Revista Teias, Rio de Janeiro, v. 21, n. 61, p. 274-286, abr./jun. 2020. DOI:

https://doi.org/10.12957/teias.2020.43792. Disponível em: www.epublicacoes.uerj.br/index.php/revistateias/article/view/43792. Acesso em: 15 mar. 2021. 


\section{Dialogia}

SALGADO, Marilda Capitulina Costa; SILVA, Marta Regina Paulo da. Do senso comum à qualificação profissional: a construção da docência de bebês

TARDOS, Anna. Introdução. In: TARDOS, Anna. El adulto y el juego del niño. Barcelona: Octaedro, 2014. p. 9-12. 